Research Article

\title{
Immobilization of Candida antarctica Lipase B on Silicone Nanofilaments
}

\author{
Noah U. Naef $(\mathbb{D})$ and Stefan Seeger $(\mathbb{C})$ \\ Department of Chemistry, University of Zurich, Zurich 8057, Switzerland \\ Correspondence should be addressed to Stefan Seeger; sseeger@chem.uzh.ch
}

Received 28 September 2020; Revised 30 November 2020; Accepted 13 January 2021; Published 8 February 2021

Academic Editor: Hassan Karimi-Maleh

Copyright (c) 2021 Noah U. Naef and Stefan Seeger. This is an open access article distributed under the Creative Commons Attribution License, which permits unrestricted use, distribution, and reproduction in any medium, provided the original work is properly cited.

Candida antarctica lipase B was immobilized on a series of silicone nanofilament-coated matrices of different porosities. In addition to creating a more open surface, SNF's hydrophobicity allows for a simple immobilization pathway via adsorption. In order to study the impact of the nanostructure, the performance was compared with control samples lacking SNFs. For all materials, the surface was characterized with BET measurements, and the immobilized enzyme was measured as well as the catalytic activity. Enzyme loads ranged between $3.85 \% \mathrm{w} / \mathrm{w}$ and $2.53 \% \mathrm{w} / \mathrm{w}$ and decreased with the decreasing surface area of the carrier material from $200 \mathrm{~m}^{2} / \mathrm{g}$ to $0.04 \mathrm{~m}^{2} / \mathrm{g}$, while the activity per enzyme increases from $824 \mathrm{U}$ to $2040 \mathrm{U}$. The data suggest that the coating seals off inner surfaces, forcing the enzyme to be immobilized at more accessible positions allowing for higher activity per enzyme. Optimization of the immobilization conditions allowed us to create a thinner enzyme layer which further improved the activity per enzyme to $3129 \mathrm{U}$. While this activity is comparable to the commercial Novozyme 435 with $3073 \mathrm{U}$, the SNF-based system performs the catalysis in a thin surface layer of around $13 \mu \mathrm{m}$. A favorite area of application is, for example, the creation of enzyme-based detection systems, where the high activity per surface area of up to $89622 \mathrm{U} \cdot \mathrm{mg} / \mathrm{m}^{2}$ would lead to high signal strength.

\section{Introduction}

The development of nanotechnology has led to multiple new developments in science ranging from the use of quantum dots to nanostructured surfaces and new functional materials [1]. Typical applications of nanotechnology are the detection of compounds of biological or environmental interest $[2,3]$ with nanocomposite electrodes. Further, the combination of physical properties and morphology has given rise to high surface and often light-driven catalysts for the removal of pollutants [4].

Silicone nanofilaments (=SNFs) are a typical example of the versatility and potential of nanomaterials. They are onedimensional polymers of polymethyl, ethyl, or vinyl siloxanes of amorphous nature [5]. They can be easily created on a multitude of surfaces in a vapor phase reaction without ele- vated pressure or temperature $[6,7]$. The created coating has a layer thickness of up to $13 \mu \mathrm{m}$ while single SNFs have an average diameter of $0.1 \mu \mathrm{m}$ with large variations depending on the chosen reaction conditions. Only $2.8 \%$ of the layer volume is occupied by SNFs, creating a highly accessible surface area [8]. Their unique growth mechanism causes hydrophobic ethyl or methyl residues to face towards the outside [9]. This orientation provides a SNF layer with a hydrophobic surface and a nanoscale roughness resulting in exceptional water-repellent properties [6]. Modifications with fluorinated carbon chains add oil-repellent properties, turning the surface superomniphobic [10]. This chemical and functional versatility has led to the attachment of many functional groups and catalysts $[11,12]$. SNFs created with vinyl groups are perfectly suitable for the thiol-ene click reaction, widening the available surfaces to anything with a thiol group 
$[13,14]$. The focus of SNF research has been the creation of functional, in most cases catalytic, surfaces with improved resilience due to hydrophobic or omniphobic properties [15]. However, their potential as a carrier of biocatalysts has so far been neglected.

Lipases are the ideal choice, because they can be immobilized by adsorption on hydrophobic surfaces with very good results [16-18]. They are highly versatile enzymes and can catalyze a wide range of reactions such as ester hydrolysis, transesterification, as well as esterification, and amidation [19-21]. Under appropriate conditions, they will react in an enantioselective manner, which allows for efficient synthesis of chiral molecules with amines, alcohols, esters, or amides located on the stereocenter [22, 23]. Practical applications include the production of biodiesel, processing of food oils, and the synthesis of chiral molecules such as pesticides or drugs [24].

Lipases are insoluble in organic solvents, although many of their substrates only dissolve in nonpolar solvents and several reactions catalyzed by lipases are water sensitive. The common solution is to immobilize the enzyme as a fine layer over a large surface to optimize the mass transfer of this heterogeneous catalyst [25]. Immobilization may have additional benefits such as increasing the resistance against catalyst denaturation or retaining the enzyme in the catalyst bed of the flow through a reactor or simplifying the removal of the catalyst.

In this study, the immobilization of Candida antarctica lipase B (=CalB) via adsorption on a series of SNF-coated silica was studied. The benefits of the SNF nanostructure were studied, and the enzyme loading was optimized. The best catalyst was then chosen and compared to the commercial immobilized CalB Novozyme 435.

\section{Materials and Methods}

2.1. Materials. Ethyltrichlorosilane (ETCS) (98\% purity) was obtained from abcr GMBH and stored under nitrogen. Silica gel (Davisil Grade 643) pore size $150 \AA$, 200-425 mesh; silica gel high-purity grade pore size $60 \AA 220$-440 mesh; glass beads $75 \mu \mathrm{m}$ acid washed; Candida antarctica lipase B, recombinant from Aspergillus oryzae (CalB); Novozyme 435 ; 4-nitrophenyl acetate ( $\geq 98 \%)$; 4-nitrophenol (spectrophotometric grade); and dioxane anhydrous $99.8 \%$ were obtained from Sigma and used as received. The Pierce ${ }^{\mathrm{TM}}$ BCA Protein Assay Kit was obtained from Thermo Fisher Scientific. CHROMAFIL Xtra PET-20/13 filter membranes were obtained from Macherey-Nagel.

2.2. Silicon Nanofilament (SNF) Coating. Silica (4g) was washed in $100 \mathrm{~mL}$ potassium hydroxide solution $(100 \mathrm{mM})$ at $50^{\circ} \mathrm{C}$ and $10 \mathrm{~W}$ sonication for $20 \mathrm{~min}$. The material was washed 7 times with distilled water $(100 \mathrm{~mL})$ and dried overnight at $100^{\circ} \mathrm{C}$. Glass beads were cleaned in oxygen plasma for 30 minutes prior to coating. The respective material (500 mg) was placed in a custom-made gas-phase reaction chamber (volume $6.5 \mathrm{~L}$ ). The relative humidity was controlled by flushing the chamber at $60 \%$ relative humidity (=RH60) (for SNFs) or RH5 (hydrophobic surface) for $8 \mathrm{~h}$.
The flow was stopped; ETCS $(600 \mu \mathrm{L})$ was injected onto a silane holder placed $10 \mathrm{~cm}$ above the sample in the middle of the chamber. The reaction was left overnight.

2.3. Lipase Immobilization. SNF-coated material (100 mg) was mixed with $0.5 \mathrm{~mL}$ ethanol, and then, $2 \mathrm{~mL}$ of potassium phosphate buffer ( $100 \mathrm{mM}, \mathrm{pH} 6.8)$ containing the appropriate amount of CalB was added. The mixture was incubated for $23 \mathrm{~h}$; then, the matrix was filtered off and washed. The catalyst had dried after $24 \mathrm{~h}$ of storage at $5^{\circ} \mathrm{C}$ and could be kept under these conditions.

2.4. Bicinchoninic Acid Assay. The protein content of the washing solution was tested using the commercial BCA assay kit in a 96-well plate [26]. The samples were incubated for $50 \mathrm{~min}$ at $37^{\circ} \mathrm{C}$, and the absorption at $562 \mathrm{~nm}$ was measured with a BioTek PowerWave XS2 plate reader. By comparison to a CalB standard curve added to each well plate, the concentrations were calculated. The enzyme loading was calculated by subtraction from the initially used CalB amount.

2.5. Activity Assay. Reaction solution containing $40 \mathrm{mM}$ para-nitophenyl acetate and $80 \mathrm{mM}$ methanol in dioxane was heated to $35^{\circ} \mathrm{C}$. The catalyst was placed in a glass vial, and $5 \mathrm{~mL}$ of the above reaction solution was added. The mixture was shaken at $200 \mathrm{rpm}$ and kept at $35^{\circ} \mathrm{C}$. After $50 \mathrm{~min}$, $0.6 \mathrm{~mL}$ aliquots were filtered off through a $22 \mu \mathrm{m}$ membrane. The absorption at $405 \mathrm{~nm}$ was measured with a Perkin-Elmer Lambda $650 \mathrm{~S} \mathrm{UV} / \mathrm{vis}$ spectrometer and compared to a standard curve to calculate the activity. One unit was defined as one nanomole of product formed per minute per mg immobilized enzyme.

2.6. Characterization. Samples for the scattering electron microscope (=SEM) were sputtered with $8 \mathrm{~nm}$ platinum with a Safematic CCU-010 HV coating unit. SEM analysis was performed on a Zeiss Supra $50 \mathrm{VP}$ at $3 \mathrm{kV}$ using the SE2 detector. Samples for nitrogen sorption isotherms were degassed under vacuum overnight at $110^{\circ} \mathrm{C}$ and measured with a Quantachrome Quadrasorb SI porosimeter. Adsorption branch points in the range $0.05<p / p 0<0.35$ were applied in the BET model.

2.7. Statistical Analysis. Errors are generally given as the standard deviation of at least 3 replicates while the results are reported as the average thereof.

\section{Results and Discussion}

3.1. Characterization of the Carrier Material. Three types of commercially available silica particles were coated and evaluated to find the optimal matrix material. The three chosen materials were silica particles $35-70 \mu \mathrm{m}$ diameter with $150 \AA$ average pore size, $35-75 \mu \mathrm{m}$ diameter with $60 \AA$ average pore size, and glass spheres of $75 \mu \mathrm{m}$ diameter without pores (see Figure 1).

Under identical coating conditions, the glass spheres had a significantly thicker SNF coating. This result indicated that the pores interfered with the coating process. To distinguish between the effect of the hydrophobic surface and the SNF 
$150 \mathrm{~A}$

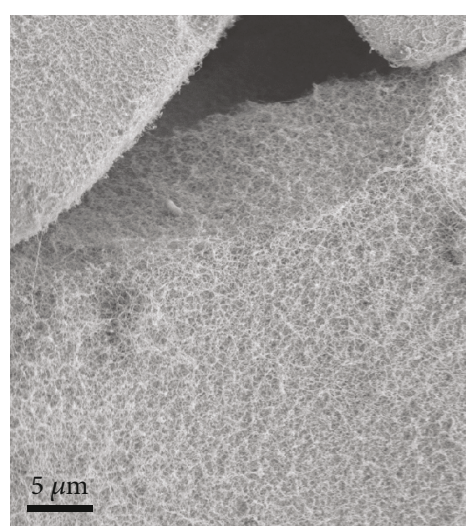

(a)
$60 \mathrm{~A}$

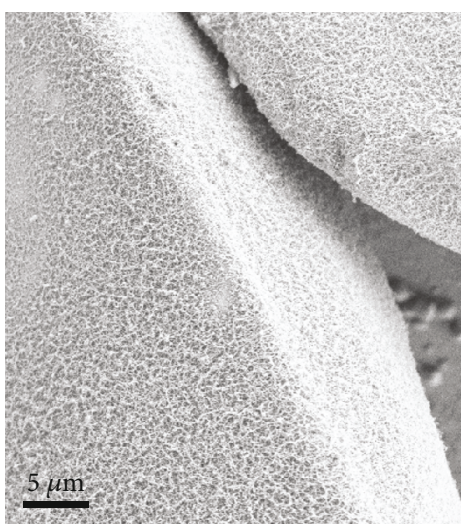

(b)

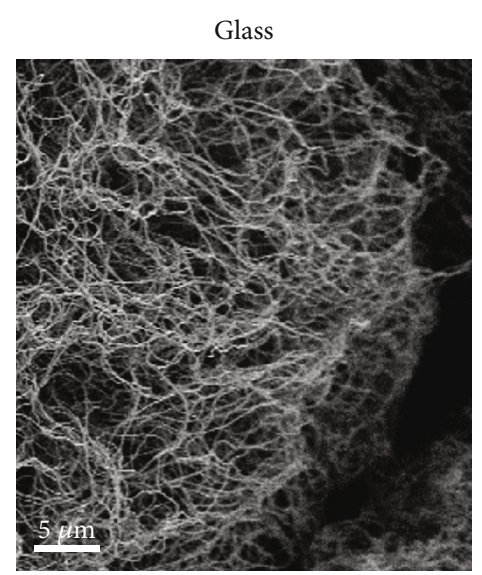

(c)

FIGURE 1: SEM pictures of 35-70 $\mu \mathrm{m}$ diameter $150 \AA$ A pore size silica, $35-75 \mu \mathrm{m}$ diameter $60 \AA$ pore size silica, and $75 \mu \mathrm{m}$ diameter glass spheres coated at $60 \%$ relative humidity $(=\mathrm{RH})(\mathrm{a}-\mathrm{c})$.

coating, a series of carriers with a hydrophobic surface, but lacking the SNFs, was created (=hydrophobic). We coated the samples at $5 \%$ relative humidity which was too low for the growth of SNFs. However, silanization still occurred, leading to a comparable hydrophobic surface free of nanostructures (see Figure 2).

The hydrophobic control samples did not differ visually from the untreated materials when examined by SEM (see supporting information Figure 1). Nitrogen sorption measurements were conducted on all created materials and applied to the Brunauer-Emmett-Teller (BET) model to obtain the total surface area the enzyme immobilization and catalysis would take place on. Furthermore, changes in the BET surface among the samples convey information about how the introduced modifications affected the pores, as the majority of the surface is pore surface and thereby all changes in the pores will heavily affect the measured surface area.

Two situations prevail, depending on the porosity of the material. The surface area of porous materials decreases in the order from untreated to hydrophobic to SNFs (see Figure 3). In the nonporous hydrophobic sample, the outer surface of particles of this size is in the range of $0.04 \mathrm{~m}^{2} / \mathrm{g}$. Even when assuming a 5 times lower density and doubling the area to account for the shard-like shape of the particles, the estimated outer surface was only $0.2 \mathrm{~m}^{2} / \mathrm{g}$. Therefore, most of the measured surface of the porous materials stemmed from the internal surface, and the significant decrease of surface area occurring during the silanization is caused by the sealing or narrowing of the pores. This outcome can be explained by the growth mechanism of SNFs [9]. During the modification, the reaction chamber was flushed for $8 \mathrm{~h}$ with nitrogen at $5 \%$ (hydrophobic) or $60 \%$ (SNFs) relative humidity. During this period, the air humidity equilibrated with the entire surface. Due to capillary forces, water condenses more readily, the narrower a specific section of a pore, or the higher the water vapor pressure is. When the ethyltrichlorosilane is injected, silanization occurs inside the condensed water, sealing off pores, and in the case of high humidity, causing the growth of SNFs. If water was to merely condense along the walls, silanization would result in narrower pores. This internal silanization effect overshadows any outer surface created by the SNFs as well as affecting the growth of SNFs, resulting in a thinner SNF carped than the one achieved on the nonporous material under identical conditions (see Figure 1). For the nonporous hydrophobic sample, the surface area of $0.04 \mathrm{~m}^{2} / \mathrm{g}$ was precisely calculated via density and size (see supporting information Table 2). 


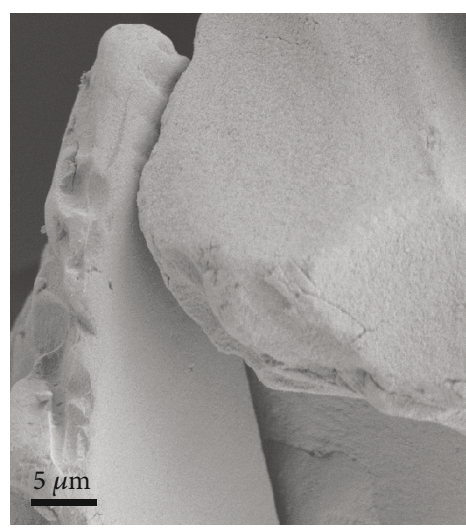

(a)

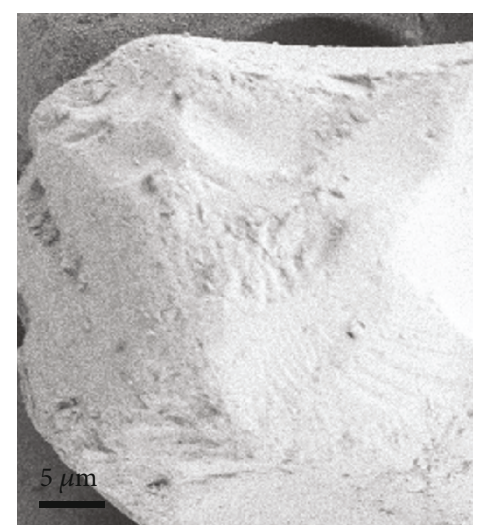

(b)

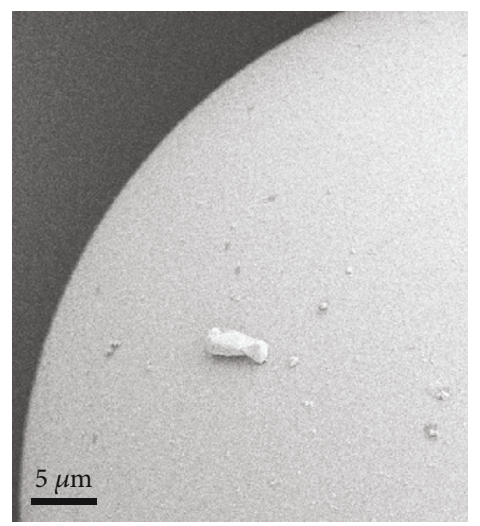

(c)

FIGURE 2: SEM pictures of 35-70 $\mu \mathrm{m}$ diameter $150 \AA$ pore size silica, $35-75 \mu \mathrm{m}$ diameter $60 \AA$ pore size silica, and $75 \mu \mathrm{m}$ diameter glass spheres coated at RH5 $(\mathrm{a}-\mathrm{c})$.

Employing large amounts of SNF-coated material, the BET surface of the coated material was measured to be $0.6 \mathrm{~m}^{2} / \mathrm{g}$ with a considerably large error of $20 \%$ due to the low total surface area. When dividing this area of $0.6 \mathrm{~m}^{2} / \mathrm{g}$ by the underlying surface of $0.04 \mathrm{~m}^{2} / \mathrm{g}$, which is the surface of the nonporous hydrophobic spheres, we may determine that the underlying surface is amplified by a factor of 15 , a feature also referred to as roughness. This roughness is in accordance with the 13-fold increase reported for ethyltrichlorosilane nanofilaments using focused ion beam nanotomography [8].

3.2. Enzyme Immobilization on the Matrix Materials. In the next step, each material was incubated in CalB solution and the enzyme concentration was determined with the bicinchoninic acid assay. The activity was measured with the paranitophenyl acetate assay where CalB catalyzes the formation of para-nitrophenol from para-nitophenyl. Combining these two results for the activity per mg immobilized enzyme, hereafter referred to as activity, allowed us to compare the performance of the created catalysts.

3.3. Enzyme Loading. The enzyme loading increased with increasing pore size (see Figure 4). In addition, hydrophobic material carried more enzyme than SNF-coated material. The exceptions were the nonporous materials where the for- mation of SNFs resulted in an overall increase in surface area that translated to an increase in enzyme loading (see Figure 3). The parameters of the average pore size of the base material and silanization conditions determined the number of sufficiently large pores to accommodate CalB with its approximate dimension of $\sim 30 \AA \times 40 \AA \times 50 \AA$ [27]. This in turn heavily influenced the enzyme loading. A larger average pore size in the material resulted in a greater number of pores in the size range above the threshold that can accommodate CalB. Further, the previously discussed silanization effect results in the filling and/or narrowing of pores resulting in SNF-coated silica particles having less enzyme than their hydrophobic counterparts. This feature is most apparent when comparing $150 \AA$ hydrophobic silica to $150 \AA$ SNFs where numerous pores fell below the threshold, resulting in a decrease in enzyme loading of $0.37 \% w / w$. The other three porous catalysts (150 $\mathrm{ANF}, 60 \AA$ hydrophobic, and $60 \AA$ SNF) followed the general trend $(150 \AA>60 \AA>$ no pores and hydrophobic $>$ SNFs), even though the differences in enzyme loading were comparably small. This outcome occurs because most of the pores have become too small, diminishing the impact of further sealing of the pores. The same results would be observed if the pores had become too narrow and the enzymes clogged the pore upon entering. This could be caused by a reduction of average diameter (150 A to $60 \AA$ A hydrophobic) or silanization making the pores 


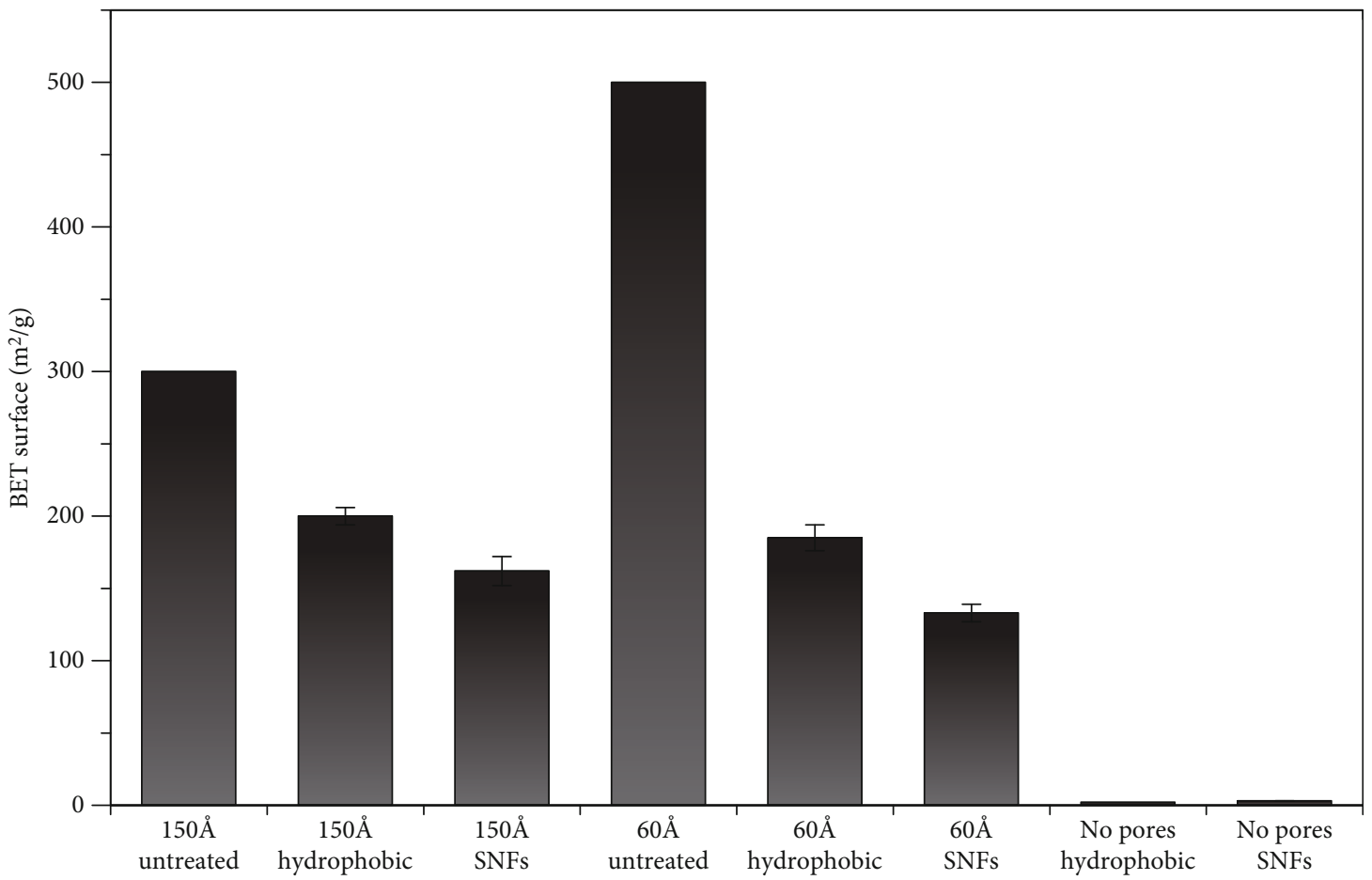

FIGURE 3: Comparison of surface areas of the different nanomaterials. The surface areas were determined by the nitrogen sorption method and applied to the Brunauer-Emmett-Teller (BET) model. Errors are generally given as the standard deviation of 3 replicates while the results are reported as the average thereof (see supporting information, Tables 1 and 2).

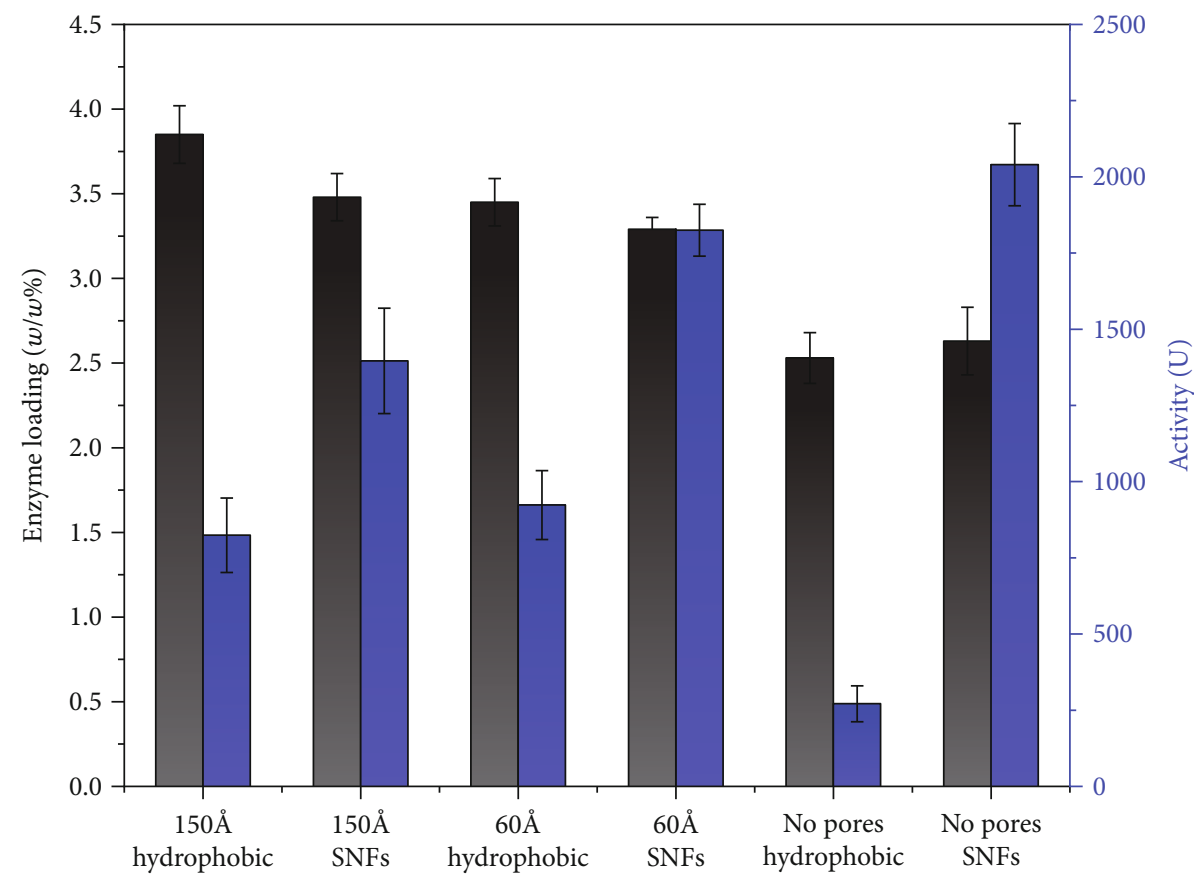

Figure 4: Comparison of enzyme loading (black) and enzyme activity (blue) on different nanomaterials. A unit of activity is defined as a nanomole of substrate converted to product per minute per mg immobilized CalB. Errors are given as the standard deviation of at least 3 measurements while the results are reported as the average thereof (see supporting information, Tables 3 and 4). 


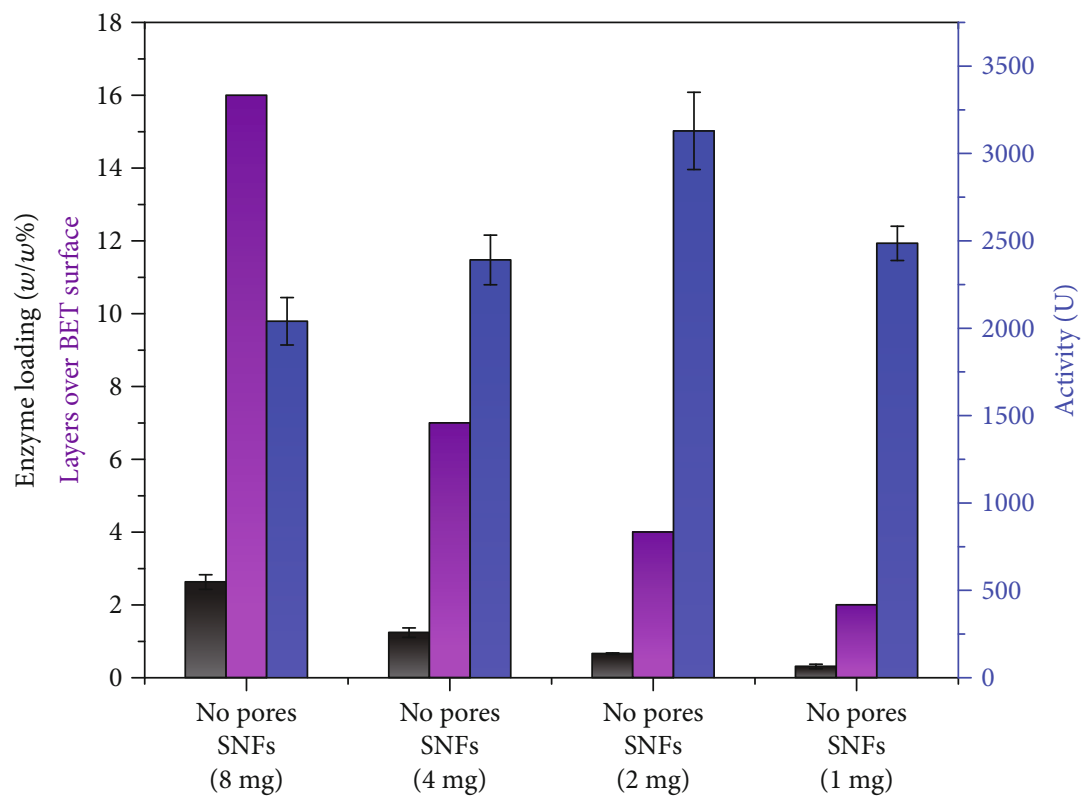

FIGURE 5: Enzyme loading (black), layers over BET surface (purple), and activity (blue) of catalyst with different amounts of CalB used in the immobilization step. Errors are given as the standard deviation of at least 3 measurements while the results are reported as the average thereof (see supporting information, Tables 5-8).

narrower (60 $\AA$ hydrophobic to $60 \AA \mathrm{SNF})$. If the pores quickly become blocked, differences in the size of available pores would result in very small differences in enzyme loading similar to what is observed in Figure 3.

3.4. Activity. The presence of SNFs clearly increased the activity compared to the corresponding hydrophobic catalyst (see Figure 4). The activity improved from $824 \mathrm{U}$ to $1396 \mathrm{U}$ for $150 \AA$ material, $923 \mathrm{U}$ to $1825 \mathrm{U}$ for $60 \AA$ material, and from $267 \mathrm{U}$ to $2040 \mathrm{U}$ for the nonporous material. The activity increased with decreasing enzyme loading for SNF-coated materials. As discussed above, the decrease in the BET surface must be caused by the sealing or narrowing of the pores. This outcome would reduce the amount of enzyme that can be immobilized in the pores (see Figure 3). The decreased capacity of the pores results in a decrease in the total enzyme loading (see Figure 4). Because the outer surface area is unaffected by the silanization process (for hydrophobic samples) or is even increased (for SNF samples), a higher percentage of the enzyme must be located on the outside as the enzyme loading decreases. Because the enzyme on the surface or located on SNFs is more exposed to the reaction solution, the mass transfer is improved, leading to more catalysis and increased activity per enzyme, thereby explaining the inversed relation between activity and BET surface. However, a more quantitative analysis of these correlations is difficult because for each of the porous materials, the fraction of the surface area that is involved in immobilization is not known.

Notably, hydrophobic and SNF surfaces presented different activities. The presence of SNF provides a more accessible outer surface, resulting in a finer spread of CalB over the surface that creates a thinner enzyme layer. In turn, better mass transfer occurs as can be seen with the nonporous substrate where the presence of SNFs resulted in a 7.5-fold increase in activity
(Figure 4). Interestingly, the enzyme activity of the nonporous hydrophobic material is lower than that with the $60 \AA$ hydrophobic material, even though all the enzyme is necessarily located on the surface of the nonporous substrate. In this case, too much enzyme was attached per unit of surface area, severely decreasing the activity of the immobilized enzyme. The same is true for the nonporous SNF sample; however, in this case, the enzyme is dispersed over a larger surface. This reduces the mass transfer problem and ultimately results in the slight increase in activity observed with no pores SNF as compared to $60 \AA$ SNF. Considering that pores interfered with the formation of SNFs and did not provide a favorable surface area, all further studies were conducted with the nonporous SNF material.

3.5. Optimization of the Enzyme Loading. Assuming a surface area occupied by CalB of $40 \AA \times 50 \AA$ based on a published crystal structure [27], we approximated that the $2.63 \mathrm{mg}$ CalB immobilized on $100 \mathrm{mg}$ of support of the most active system (no pore SNFs) would be sufficient to create $\sim 16$ monolayers over the entire BET surface of the nonporous catalyst (see supporting information Table 7). While this approximation may have a large error, it suggests that substrate diffusion through this enzyme layer could be limiting the activity of the immobilized enzyme. Therefore, the amount of enzyme provided during the immobilization protocol was decreased, and the resulting enzyme loading and activity were measured.

Decreasing the enzyme loading to $0.66 \%$ increased the activity to $3129 \mathrm{U}$ (see Figure 5). Further reduction of the immobilized enzyme gave no additional benefit. Thus, the supply of reactant through the enzyme layer is no longer the limiting factor. It is not clear why the activity decreased when only $1 \mathrm{mg}$ CalB was offered during the immobilization. Interactions between the adsorbed enzymes could play a crucial role. Such interactions could provide conformational 
TABLE 1: Comparison of the SNF-based catalysts to the commercial Novozyme 435. The errors of the activity per BET surface were calculated with the error propagation formula. The enzyme loading and BET surface of Novozyme 435 were taken from the literature [18, 30]. See supporting information Table 7 for the approximation of the layers over the BET surface. Errors are given as the standard deviation of at least 3 measurements while the results are reported as the average thereof (see supporting information Table 8).

\begin{tabular}{|c|c|c|c|c|c|}
\hline & $\begin{array}{l}\text { Activity } \\
\text { (U) }\end{array}$ & $\begin{array}{c}\text { Immobilized CalB } \\
(w / w \%)\end{array}$ & $\begin{array}{c}\text { BET surface } \\
\left(\mathrm{m}^{2} / \mathrm{g}\right)\end{array}$ & $\begin{array}{c}\text { Layers over BET } \\
\text { surface }\end{array}$ & $\begin{array}{c}\text { Activity per BET surface } \\
\left(\mathrm{U} \cdot \mathrm{mg} / \mathrm{m}^{2}\right)\end{array}$ \\
\hline $\begin{array}{l}\text { No pores SNFs } \\
(8 \mathrm{mg})\end{array}$ & $2040( \pm 136)$ & $2.6 \pm 0.2$ & $0.6 \pm 0.1$ & 16 & $89622 \pm 17459$ \\
\hline $\begin{array}{l}\text { No pores SNFs } \\
(4 \mathrm{mg})\end{array}$ & $2391( \pm 164)$ & $1.2 \pm 0.1$ & $0.6 \pm 0.1$ & 7 & $49462 \pm 10127$ \\
\hline $\begin{array}{l}\text { No pores SNFs } \\
(2 \mathrm{mg})\end{array}$ & $3129( \pm 199)$ & $0.7 \pm 0.1$ & $0.6 \pm 0.1$ & 4 & $34661 \pm 6364$ \\
\hline $\begin{array}{l}\text { No pores SNFs } \\
(1 \mathrm{mg})\end{array}$ & $2566( \pm 62)$ & $0.3 \pm 0.1$ & $0.6 \pm 0.1$ & 2 & $13012 \pm 3232$ \\
\hline Novozyme 435 & $3073( \pm 269)$ & 20 & 150 & 0.5 & $4098 \pm 359$ \\
\hline
\end{tabular}

stability for the enzyme and prevent denaturation during the reaction. The high activity reported for crosslinked lipase aggregates in the literature which occurred when enzymes were closely packed supports this explanation [28].

3.6. Comparison to a Commercial Catalyst. We compared the performance of our system to Novozyme 435, a commercial immobilized CalB consisting of porous acrylic resin beads [29]. Specifically, the activity per surface area was considered, because in the SNF-based system the catalysis is performed on a thin surface rather than in the bulk material.

The experimental conditions applied led to a comparable activity to Novozyme 435 if the SNF-based system was used. However, the SNF-based system has higher activity per surface area (see Table 1). In terms of the activity per enzyme optimized system, no pores SNFs ( $2 \mathrm{mg}$ ) is 4.8 times more efficient per surface area than Novozyme 435 . However, surfaces of up to $89622 \mathrm{U} \cdot \mathrm{mg} / \mathrm{m}^{2}$, i.e., 12 times higher efficiency, can be achieved (no pores SNFs ( $8 \mathrm{mg})$ ). This surface activity stems predominantly from the higher enzyme loading per BET surface achieved with SNFs.

\section{Conclusion}

CalB was successfully immobilized on SNF-modified materials. The advantages of SNF-coated materials over their nanostructure-free counterparts were clearly demonstrated. The presence of SNFs resulted in an up to 7.5-fold increase in activity compared to the same base material with hydrophobic surface chemistry. Further improvements on the system were achieved by optimizing the catalyst loading, moving from 2040 to $3129 \mathrm{U}$ when using the nonporous material. While the presence of pores was generally inferior compared to the absence of pores, for the purpose of CalB immobilization, the silanization process nonetheless offers a simple solvent-free approach to create hydrophobic porous silica. When considering the high activity per area and transparent nature of the SNF coating, the system has great potential for the creation of enzyme-based fiber optic or microfluidic analysis systems [31, 32]. In these examples, enzymes have been immobilized on a filter membrane in contact with glass fiber. Upon contact with the enzyme's substrate, a reaction is catalyzed that is translated into a change of absorption or a fluorescent signal that is directed into the glass fiber, with the response correlating to the substrate concentration and providing the analytic result. Since SNFs can be transparent, they should not interfere with the signal and could be coated directly on the fiber opening, simplifying the construction of such detection systems.

\section{Data Availability}

Additional data, beyond what is provided in the supporting information, are available from the corresponding author upon request.

\section{Conflicts of Interest}

The authors declare that there is no conflict of interest regarding the publication of this paper.

\section{Acknowledgments}

We thank the Center for Microscopy and Image Analysis (ZMB) of the University of Zurich for the permission to use the microscopic facilities. Further thanks are due to the Patzke group for letting us use their BET setup. We thank the Forschungskredit of the University of Zurich, grant no. FK-17-095 for financial assistance.

\section{Supplementary Materials}

The supplementary material contains SEM pictures comparing hydrophobic to untreated material, the individual experimental results, and the surface area calculations. (Supplementary Materials)

\section{References}

[1] G. M. Whitesides, "Nanoscience, nanotechnology, and chemistry," Small, vol. 1, no. 2, pp. 172-179, 2005.

[2] H. Karimi-Maleh, F. Karimi, Y. Orooji et al., "A new nickelbased co-crystal complex electrocatalyst amplified by $\mathrm{NiO}$ 
dope Pt nanostructure hybrid; a highly sensitive approach for determination of cysteamine in the presence of serotonin," Scientific Reports, vol. 10, no. 1, article 11699, 2020.

[3] M. Ghanei-Motlagh and M. Baghayeri, "Determination of trace $\mathrm{Tl}(\mathrm{I})$ by differential pulse anodic stripping voltammetry using a novel modified carbon paste electrode," Journal of the Electrochemical Society, vol. 167, no. 6, article 066508, 2020.

[4] H. Karimi-Maleh, B. G. Kumar, S. Rajendran et al., "Tuning of metal oxides photocatalytic performance using Ag nanoparticles integration," Journal of Molecular Liquids, vol. 314, p. $113588,2020$.

[5] G. R. J. Artus and S. Seeger, "One-dimensional silicone nanofilaments," Advances in Colloid and Interface Science, vol. 209, pp. 144-162, 2014.

[6] J. Zimmermann, G. R. J. Artus, and S. Seeger, "Superhydrophobic silicone nanofilament coatings," Journal of Adhesion Science and Technology, vol. 22, no. 3-4, pp. 251-263, 2008.

[7] G. R. J. Artus, L. Bigler, and S. Seeger, "Superficial dopants allow growth of silicone nanofilaments on hydroxyl-free substrates," Langmuir, vol. 30, no. 34, pp. 10308-10316, 2014.

[8] G. R. Meseck, A. Käch, and S. Seeger, "Three-dimensional organization of surface-bound silicone nanofilaments revealed by focused ion beam nanotomography," Journal of Physical Chemistry C, vol. 118, no. 43, pp. 24967-24975, 2014.

[9] G. R. J. Artus, S. Olveira, D. Patra, and S. Seeger, "Directed in situ shaping of complex nano- and microstructures during chemical synthesis," Macromolecular Rapid Communications, vol. 38, no. 4, pp. 1-9, 2017.

[10] J. Zhang and S. Seeger, "Superoleophobic coatings with ultralow sliding angles based on silicone nanofilaments," Angewandte Chemie International Edition, vol. 50, no. 29, pp. 6652-6656, 2011.

[11] M. Meier, A. Suppiger, L. Eberl, and S. Seeger, "Functional silver-silicone-nanofilament-composite material for water disinfection," Small, vol. 13, no. 4, article 1601072, 2017.

[12] Z. Chu and S. Seeger, "Multifunctional hybrid porous micro/nanocomposite materials," Advanced Materials, vol. 27, no. 47, pp. 7775-7781, 2015.

[13] J. Li, L. Li, X. du et al., "Reactive superhydrophobic surface and its photoinduced disulfide-ene and thiol-ene (Bio)functionalization," Nano Letters, vol. 15, no. 1, pp. 675-681, 2015.

[14] A. B. Lowe, "Thiol-ene 'click' reactions and recent applications in polymer and materials synthesis," Polymer Chemistry, vol. 1, no. 1, pp. 17-36, 2010.

[15] N.-u.-H. Saddiqi, D. Patra, and S. Seeger, "Room Temperature synthesis of germanium oxide nanofilaments and their potential use as luminescent self-cleaning surfaces," ChemPhysChem, vol. 20, no. 4, pp. 538-544, 2018.

[16] U. Hanefeld, L. Gardossi, and E. Magner, "Understanding enzyme immobilisation," Chemical Society Reviews, vol. 38, no. 2, pp. 453-468, 2009.

[17] P. Adlercreutz, "Immobilisation and application of lipases in organic media," Chemical Society Reviews, vol. 42, no. 15, pp. 6406-6436, 2013.

[18] N. Miletić, V. Abetz, K. Ebert, and K. Loos, "Immobilization of candida antarctica lipase B on polystyrene nanoparticles," Macromolecular Rapid Communications, vol. 31, no. 1, pp. 71-74, 2010.

[19] W. E. Ladner and G. M. Whitesides, "Lipase-catalyzed hydrolysis as a route to esters of chiral epoxy alcohols," Journal of the
American Chemical Society, vol. 106, no. 23, pp. 7250-7251, 1984.

[20] A. Bajaj, P. Lohan, P. N. Jha, and R. Mehrotra, "Biodiesel production through lipase catalyzed transesterification: an overview," Journal of Molecular Catalysis B: Enzymatic, vol. 62, no. 1, pp. 9-14, 2010.

[21] D. Manova, F. Gallier, L. Tak-Tak, L. Yotava, and N. LubinGermain, "Lipase-catalyzed amidation of carboxylic acid and amines," Tetrahedron Letters, vol. 59, no. 21, pp. 2086-2090, 2018.

[22] A. Ghanem and H. Y. Aboul-Enein, "Application of lipases in kinetic resolution of racemates," Chirality, vol. 17, no. 1, pp. 115, 2005.

[23] A. S. de Miranda, L. S. M. Miranda, and R. O. M. A. de Souza, "Lipases: valuable catalysts for dynamic kinetic resolutions," Biotechnology Advances, vol. 33, no. 5, pp. 372-393, 2015.

[24] R. DiCosimo, J. McAuliffe, A. J. Poulose, and G. Bohlmann, "Industrial use of immobilized enzymes," Chemical Society Reviews, vol. 42, no. 15, pp. 6437-6474, 2013.

[25] M. Würtz Christensen, L. Andersen, T. L. Husum, and O. Kirk, "Industrial lipase immobilization," European Journal of Lipid Science and Technology, vol. 105, no. 6, pp. 318-321, 2003.

[26] PIERCE, Pierce Protein Assay Kit Bulletin, 1296.3, Pierce Biotechnol, 2003.

[27] Y. Xie, J. An, G. Yang et al., "Enhanced enzyme kinetic stability by increasing rigidity within the active site," The Journal of Biological Chemistry, vol. 289, no. 11, pp. 7994-8006, 2014.

[28] P. Lôpez-Serrano, L. Cao, F. Van Rantwijk, and R. A. Sheldon, "Cross-linked enzyme aggregates with enhanced activity: application to lipases," Biotechnology Letters, vol. 24, no. 16, pp. 1379-1383, 2002.

[29] K. F. Haigh, S. Z. Abidin, G. T. Vladisavljević, and B. Saha, "Comparison of Novozyme 435 and Purolite D5081 as heterogeneous catalysts for the pretreatment of used cooking oil for biodiesel production," Fuel, vol. 111, pp. 186-193, 2013.

[30] B. Chen, J. Hu, E. M. Miller, W. Xie, M. Cai, and R. A. Gross, "Candida antarctica lipase B chemically immobilized on epoxy-activated micro- and nanobeads: catalysts for polyester synthesis," Biomacromolecules, vol. 9, no. 2, pp. 463-471, 2008.

[31] M. R. S. Fuh, L. W. Burgess, and G. D. Christian, "Single fiberoptic fluorescence enzyme-based sensor," Analytical Chemistry, vol. 60, no. 5, pp. 433-435, 2002.

[32] M. A. Arnold, "Enzyme-based fiber optic sensor.," Analytical Chemistry, vol. 57, no. 2, pp. 565-566, 2002. 